Article

\title{
Design, Synthesis and Antifungal Activity of Novel Benzofuran-Triazole Hybrids
}

\author{
Zhen Liang ${ }^{1}$, Hang $\mathrm{Xu}^{1}{ }^{1}, \mathrm{Ye} \mathrm{Tian}^{1}{ }^{1}$, Mengbi Guo ${ }^{1}, \mathrm{Xin} \mathrm{Su}^{2}$ and Chun Guo ${ }^{1, *}$ \\ 1 Key Laboratory of Structure-Based Drugs Design \& Discovery of Ministry of Education, \\ Shenyang Pharmaceutical University, Shenyang 110016, China; 1lzz_666@126.com (Z.L.); \\ xuhanglg2@126.com (H.X.); tianye870918@126.com (Y.T.); guomengbi@hotmail.com (M.G.) \\ 2 School of Life Sciences and Biopharmaceutics, Shenyang Pharmaceutical University, Shenyang 110016, \\ China; suxin1966@163.com \\ * Correspondence: gc_66888@163.com; Tel.: +86-24-2398-6425
}

Academic Editor: Richard A. Bunce

Received: 20 April 2016; Accepted: 1 June 2016; Published: 7 June 2016

\begin{abstract}
A series of novel benzofuran-triazole hybrids was designed and synthesized by click chemistry, and their structures were characterized by HRMS, FTIR and NMR. The in vitro antifungal activity of target compounds was evaluated using the microdilution broth method against five strains of pathogenic fungi. The result indicated that the target compounds exhibited moderate to satisfactory activity. Furthermore, molecular docking was performed to investigate the binding affinities and interaction modes between the target compound and $N$-myristoyltransferase. Based on the results, preliminary structure activity relationships (SARs) were summarized to serve as a foundation for further investigation.
\end{abstract}

Keywords: antifungal activity; $N$-myristoyltransferase; benzofuran; 1,2,3-triazole; click chemistry; molecule hybrid

\section{Introduction}

Fungal infections have posed a continuous and serious threat to human health and life during the past two decades, especially among hosts, such as patients undergoing anticancer chemotherapy or organ transplants, and patients with AIDS [1,2]. Clinically, available antifungal drugs have several drawbacks, such as drug-related toxicity, non-optimal pharmacokinetics, and the emergence of drug resistance $[3,4]$. Therefore, the development of new antifungal drugs with novel modes of action is required.

$\mathrm{N}$-Myristoyltransferase (NMT) is a monomeric enzyme that catalyzes the transfer of the myristoyl group of myristoyl-CoA to the $N$-terminal glycine of various eukaryotic cellular proteins $[5,6]$ and it was proven to be essential for the viability of pathogenic fungi, such as C. albicans [7] and C. neoformans [8]. Although NMT is also distributed in mammalian cells, there are clear differences in the peptide-substrate specificity between human and fungal NMT [9], which could be exploited to avoid adverse events caused by inhibiting human NMT. Therefore, NMT would be a promising target for the development of novel fungicidal drugs. Up to now, various types of NMT inhibitors such as peptidomimetic [10-12], myristic acid analogues [13] and different kinds of heterocycles [14-16] have been reported. Among them, benzofuran inhibitors showed high selectivity and powerful antifungal activity [16-19] (Figure 1). Furthermore, the benzofuran core itself possessed a definite antifungal activity and numbers of benzofuran derivatives were reported without indicating the targets [20-23] (Figure 1). 


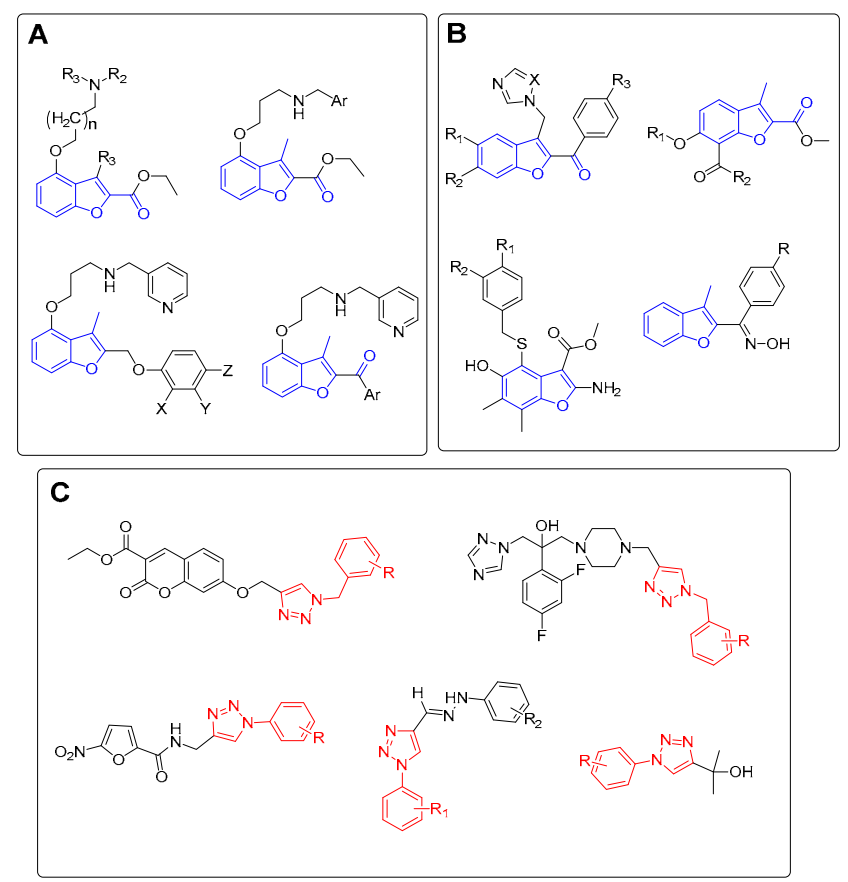

Figure 1. The representative structures of antifungal agents. (A) Representative structures of the benzofuran NMT inhibitors; (B) Representative benzofuran derivatives with antifungal activity; (C) Representative 1,2,3-triazole derivatives with antifungal activity.

In recent years, the 1,2,3-triazole scaffold became a highlight fragment with the emergence of click chemistry and the 1,2,3-triazole-containing compounds were reported to possess a variety of biological activities [24-28], especially as antifungal agents [29-31]. Furthermore, the hybridizations of the 1,2,3-triazole moiety with other antifungal agents were reported. Coumarin derivatives incorporating the 1,2,3-triazole moiety showed antifungal activity [32]. Hybrids of fluconazole with 1,2,3-triazole were proved to possess satisfactory activity [33].

Encouraged by the results above, we attempted to design and synthesize a series of benzofuran-triazole hybrids to evaluate the in vitro antifungal activity.

\section{Results and Discussion}

\subsection{Chemistry}

The synthetic route to target compounds was outlined in Scheme 1 . The reaction of $2^{\prime}, 6^{\prime}-$ dihydroxyacetophenone with the corresponding 2-bromoacetophenone in a modified Rap-Stormer reaction condition [22] gave the benzofuran scaffold (1). Alkylation of the hydroxyl group of $\mathbf{1 a}, \mathbf{b}$ with propargyl bromide gave terminal alkyne derivatives $(\mathbf{2} \mathbf{a}, \mathbf{b})$. The aromatic azides $(\mathbf{3} \mathbf{a}-\mathbf{i})$ were prepared from the corresponding anilines following the Sandmeyer conditions [27,31]. Finally, employing click chemistry, compounds $\mathbf{2} \mathbf{a}, \mathbf{b}$ were cyclized with $\mathbf{3} \mathbf{a}-\mathbf{i}$, respectively, to give target compounds $\mathbf{4 a - r}$ in good yields.

\subsection{Antifungal Activity}

The in vitro antifungal activity of the target compounds was measured by means of the minimal inhibitory concentrations (MICs) with fluconazole as the control drug. The results are summarized in Table 1. Against fluconazole-resistant Trichophyton rubrum, many target compounds $(\mathbf{4 e}, \mathbf{f}, \mathbf{4 h}$ and $4 \mathbf{b}-\mathbf{r})$ showed better activity than fluconazole $\left(128 \mu \mathrm{g} \cdot \mathrm{mL}^{-1}\right)$ in the range of 32 to $64 \mu \mathrm{g} \cdot \mathrm{mL}^{-1}$, and some compounds (4b, $\mathbf{4 d}, \mathbf{4 g}$, and $\mathbf{4 i - 1})$ showed equivalent activity to fluconazol. Except compounds $4 \mathbf{a}$ and $\mathbf{4 c}$, most of the compounds showed antifungal activity against Cryptococcus neoformans in 
concentrations ranging from 32 to $128 \mu \mathrm{g} \cdot \mathrm{mL}^{-1}$. The target compounds $(\mathbf{4 f}, \mathbf{4 h}, \mathbf{4 m}, \mathbf{4 p}$ and $\mathbf{4 r}$ ) showed antifungal activity against Candida zeylanoides at the concentration of $64 \mu \mathrm{g} \cdot \mathrm{mL}^{-1}$. Some compounds showed weak activity merely against Candida albicans (4f, $4 \mathbf{h}, \mathbf{4 m}, \mathbf{4 o}$ and $\mathbf{4 r}$ ) and Rhodotorula rubra (4d, 4f, $4 \mathbf{h}, \mathbf{4 o}$ and $\mathbf{4 q}, \mathbf{r}$ ) at the concentration of $128 \mu \mathrm{g} \cdot \mathrm{mL}^{-1}$.<smiles>[R]c1cc(F)ccc1C(=O)CBr</smiles>

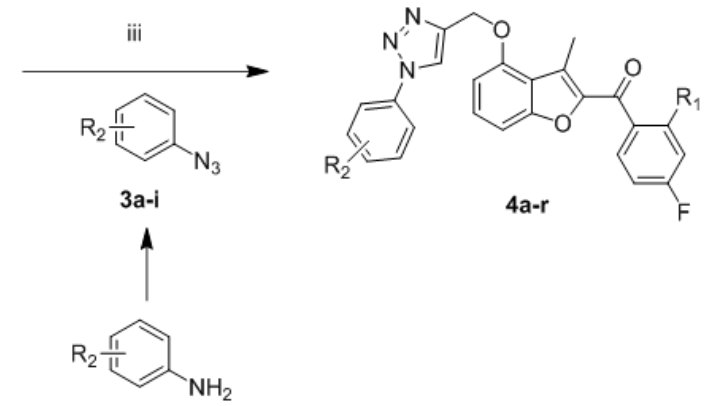

$$
\begin{aligned}
& \mathrm{R}_{1}=\mathrm{H} \quad 1 \mathrm{a}, 2 \mathrm{a}, 4 \mathrm{a}-\mathrm{i} \\
& R_{1}=F \quad 1 b, 2 b, 4 j-r \\
& \mathrm{R}_{2}=4-\mathrm{Cl} \quad 4 \mathrm{a}, 4 \mathrm{j} \\
& \mathrm{R}_{2}=2-\mathrm{Cl} \quad 4 \mathrm{~b}, 4 \mathrm{k} \\
& \mathrm{R}_{2}=4-\mathrm{Br} \quad 4 \mathrm{c}, 4 \mathrm{I} \\
& \mathrm{R}_{2}=2-\mathrm{Br} \quad 4 \mathrm{~d}, 4 \mathrm{~m} \\
& \mathrm{R}_{2}=4-\mathrm{CH}_{3} \quad 4 \mathrm{e}, 4 \mathrm{n} \\
& \mathrm{R}_{2}=2-\mathrm{CH}_{3} \quad 4 \mathrm{f}, 40 \\
& \mathrm{R}_{2}=2-\mathrm{CH}_{2} \mathrm{CH}_{3} \quad 4 \mathrm{~g}, 4 \mathrm{p} \\
& \mathrm{R}_{2}=2,6-\mathrm{di}-\mathrm{CH}_{3} \quad 4 \mathrm{~h}, 4 \mathrm{q} \\
& \mathrm{R}_{2}=2,5-\mathrm{di}-\mathrm{CH}_{3} \quad 4 \mathrm{i}, 4 \mathrm{r}
\end{aligned}
$$

Scheme 1. Synthesis of target compounds 4a-r. Reagents and conditions: (i) $\mathrm{K}_{2} \mathrm{CO}_{3} / \mathrm{CH}_{3} \mathrm{CN} /$ reflux 5-6 h; (ii) propargyl bromide $/ \mathrm{K}_{2} \mathrm{CO}_{3} /$ r.t. $3-5 \mathrm{~h}$; (iii) $\mathrm{CuSO}_{4} \cdot 5 \mathrm{H}_{2} \mathrm{O} /$ sodium ascorbate/DMF/r.t. $2-4$ h.

Table 1. Antifungal in vitro activities of the target compounds (MIC, $\mu \mathrm{g} \cdot \mathrm{mL}^{-1}$ ).

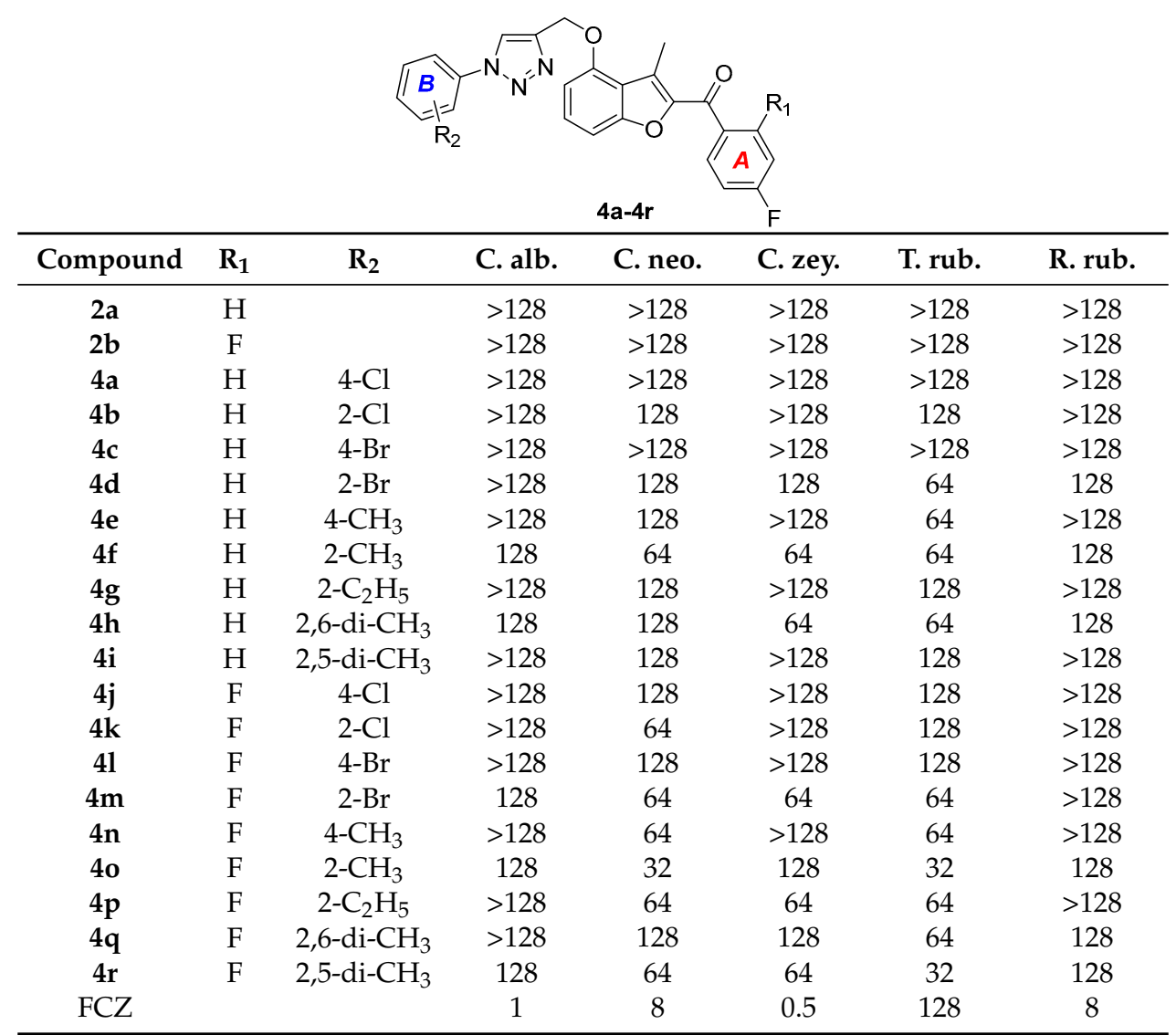

Abbreviations: C. alb., Candida albicans (CPCC400616); C. neo., Cryptococcus neoformans (CGMCC2.3161); C. zey., Candida zeylanoides (CGMCC2.3739); T. rub., Trichophyton rubrum; R. rub., Rhodotorula rubra; FCZ, Fluconazole. 
Observing the antifungal assay results, it can be noticed that the derivatives with a di-fluorinesubstituted phenyl ring at the benzofuran C-2 side chain (ring A) are more effective than the mono-fluorine ones (e.g., $4 \mathbf{f}$ vs. 4o). Meanwhile, the substituted groups on the phenyl ring linked to the triazole (ring B) also had an impact on the activity. The alkyl-substituted compounds are more potent than the halogenated derivatives (e.g., $4 \mathbf{b}$ vs. $4 \mathbf{f}$ ) and the ortho-substituted derivatives are more potent than the para isomers (e.g., $4 \mathbf{e} v s . \mathbf{4 f}, \mathbf{4 j}$ vs. $\mathbf{4 k}$ ). The preliminary structure activity relationships (SARs) were supported by the outstanding bioactivities of $4 \mathbf{o}$ and $4 \mathbf{r}$ among all the target compounds.

\subsection{Molecule Docking}

In an attempt to investigate the action modes of the target compounds, 4o was docked into the crystal structure of NMT from C. albicans (CaNMT, PDB ID: 1IYL) using Discovery Studio 3.0. The docking results are illustrated in Figure 2. The benzofuran ring was located at the center of the active site, surrounding some hydrophobic residues, such as Tyr225, Tyr354 and Leu394, and forming a pi-pi interaction with Tyr225. The di-fluorine phenyl fragment formed a hydrophobic interaction with Phe115, Phe240 and Phe339. The phenyl triazole side chain stretched into the hydrophobic pocket constituted by Phe117, Tyr119 and Phe176. The oxygen atom of the benzofuran ring formed a hydrogen bond with His227. The interaction mode between 40 and the receptor is similar to the co-crystal ligand. On the other hand, no hydrogen bond was observed between triazole and Leu451, which is formed between the C-4 secondary amine of the co-crystal ligand. This hydrogen bond is important to the antifungal activity [34]. The docking result is supported by the weak antifungal activity against $C$. albicans of the target compounds.
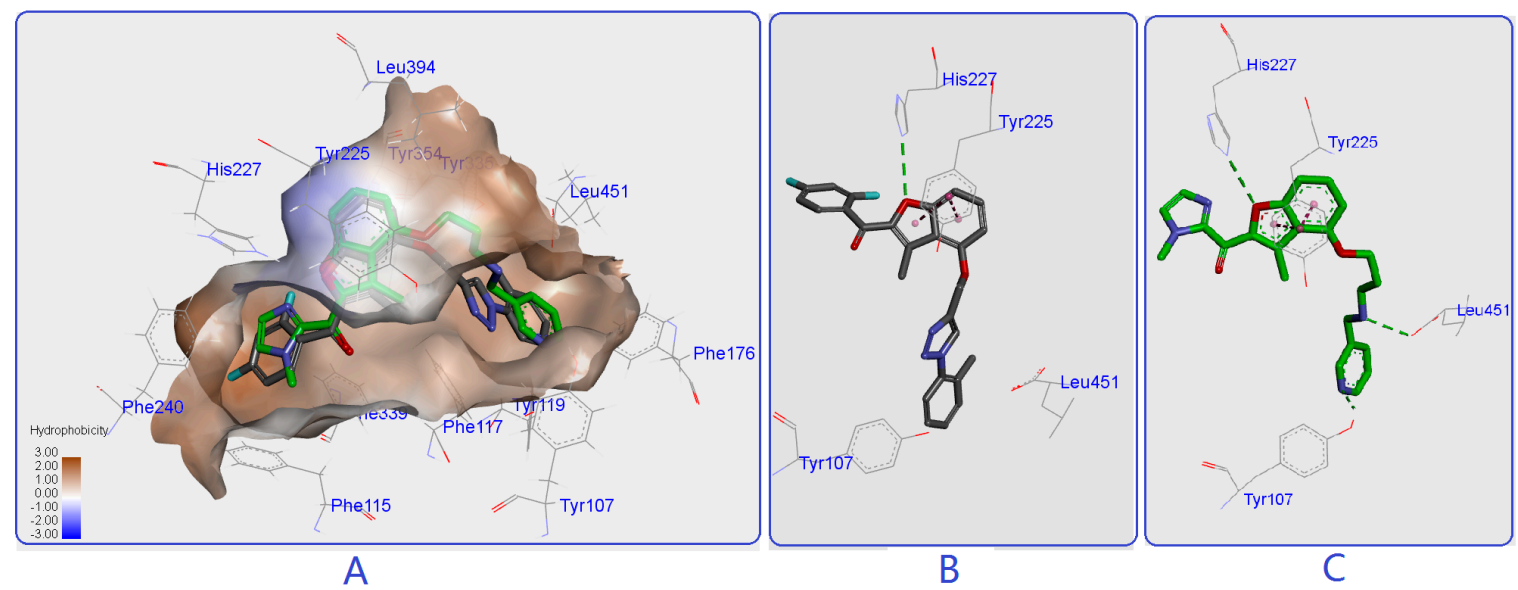

Figure 2. Molecule docking results.(A) The location of docking ligands; (B) Hydrogen bonds between $4 \mathbf{o}$ and receptor; (C) Hydrogen bonds between co-crystal ligand and receptor.

\section{Experimental Section}

\subsection{Chemistry}

The ${ }^{1} \mathrm{H}$ - and ${ }^{13} \mathrm{C}$-NMR spectra were recorded respectively on a Bruker AV-600 spectrometer and a Bruker AV-400 spectrometer. Chemical shifts were reported in parts per million (ppm, $\delta)$ downfield from TMS as an internal standard. High-resolution mass spectra (HRMS) were measured with an Agilent Accurate-Mass Q-TOF 6530 in ESI mode (Agilent, Santa Clara, CA, USA). FTIR spectra were recorded on a Bruker IFS 55 spectrometer (Bruker Co., Karlsruhe, Germany). Melting points (m.p.) were determined on an X-4 microscope melting point apparatus (Beijing Tech instrument Co., Ltd., Beijing, China) without calibration. 


\subsubsection{General Procedure for the Synthesis of Compounds $\mathbf{1 a}, \mathbf{b}$}

The 2',6'-Dihydroxyacetophenone $(7.60 \mathrm{~g}, 50 \mathrm{mmol})$, potassium carbonate $(8.30 \mathrm{~g}, 60 \mathrm{~mol})$ and substituted 4-bromoacetylbenzene $(50 \mathrm{mmol})$ were refluxed in $80 \mathrm{~mL}$ acetonitrile for six hours. After cooled to room temperature, the reaction mixture was poured into water. The crude products were filtrated and crystallized from ethanol.

2-(4-Fluorobenzoyl)-3-methyl-4-hydroxybenzofuran (1a): Yellow solid; yield 58\%. ${ }^{1} \mathrm{H}-\mathrm{NMR}(600 \mathrm{MHz}$, DMSO- $\left.d_{6}\right) \delta 10.51(\mathrm{~s}, 1 \mathrm{H}), 8.04(\mathrm{dd}, J=8.5,5.6 \mathrm{~Hz}, 2 \mathrm{H}), 7.39(\mathrm{t}, J=8.7 \mathrm{~Hz}, 2 \mathrm{H}), 7.30(\mathrm{t}, J=8.1 \mathrm{~Hz}$, $1 \mathrm{H}), 7.03(\mathrm{~d}, J=7.9 \mathrm{~Hz}, 1 \mathrm{H}), 6.68(\mathrm{~d}, J=7.9 \mathrm{~Hz}, 1 \mathrm{H}), 2.70(\mathrm{~s}, 3 \mathrm{H}) .{ }^{13} \mathrm{C}-\mathrm{NMR}(151 \mathrm{MHz}, \mathrm{DMSO}) \delta$ $183.72,165.78,164.12,155.81,155.22,146.39,134.61,132.58,132.51,130.15,128.01,117.89,115.99,115.85$, 108.47, 103.14, 12.01. IR (KBr, $\left.\mathrm{cm}^{-1}\right)$ : 3423, 2924, 1623, 1604, 1385, 1269, 1054. ESI-HRMS $(\mathrm{m} / z)$ found: 269.0619 (calcd. for $\mathrm{C}_{16} \mathrm{H}_{10} \mathrm{FO}_{3}[\mathrm{M}-\mathrm{H}]^{-}$: 269.0619).

2-(2,4-Difluorobenzoyl)-3-methyl-4-hydroxybenzofuran (1b): Yellow solid; yield 62\%. ${ }^{1} \mathrm{H}-\mathrm{NMR}(600 \mathrm{MHz}$, DMSO-d $)) \delta 10.57(\mathrm{~s}, 1 \mathrm{H}), 7.78-7.71(\mathrm{~m}, 1 \mathrm{H}), 7.46-7.43(\mathrm{~m}, 1 \mathrm{H}), 7.33-7.23(\mathrm{~m}, 2 \mathrm{H}), 6.97(\mathrm{~d}, J=7.9 \mathrm{~Hz}, 1 \mathrm{H})$, $6.67(\mathrm{~d}, J=7.9 \mathrm{~Hz}, 1 \mathrm{H}), 2.67$ (s, 3H). ${ }^{13} \mathrm{C}-\mathrm{NMR}(151 \mathrm{MHz}, \mathrm{DMSO}) \delta 181.82,165.34,163.67,156.06,155.45$, 146.27, 132.47, 130.71, 128.14, 118.05, 112.61, 112.45, 108.47, 103.07, 11.67. IR (KBr, $\left.\mathrm{cm}^{-1}\right): 3417,2925$, 1614, 1385, 1269, 1054. ESI-HRMS ( $m / z$ ) found: 287.0531 (calcd. for $\mathrm{C}_{16} \mathrm{H}_{9} \mathrm{~F}_{2} \mathrm{O}_{3}[\mathrm{M}-\mathrm{H}]^{-}: 287.0525$ ).

\subsubsection{General Procedure for the Synthesis of Compounds $\mathbf{2 a}, \mathbf{b}$}

To a solution of compound $\mathbf{1 a}$ or $\mathbf{1 b}(10.0 \mathrm{mmol})$ in DMF $(20 \mathrm{~mL})$, propargyl bromide $(1.30 \mathrm{~g}$, $10.9 \mathrm{mmol})$ and potassium carbonate $(1.70 \mathrm{~g}, 12.3 \mathrm{mmol})$ were added. The reaction mixture was stirred at room temperature for $5 \mathrm{~h}$, and was then diluted with ethyl acetate $(80 \mathrm{~mL})$ and washed with water $(2 \times 100 \mathrm{~mL})$. The organic layer was dried over anhydrous $\mathrm{Na}_{2} \mathrm{SO}_{4}$ and concentrated under reduced pressure. The crude products were used without purification.

2-(4-Fluorobenzoyl)-3-methyl-4-(propyn-3-yloxy)benzofuran (2a): Yellow solid; yield 62\%. ${ }^{1} \mathrm{H}-\mathrm{NMR}(600 \mathrm{MHz}$, DMSO- $\left.d_{6}\right) \delta 8.07-8.04(\mathrm{~m}, 2 \mathrm{H}), 7.48(\mathrm{t}, J=8.2 \mathrm{~Hz}, 1 \mathrm{H}), 7.43-7.36(\mathrm{~m}, 2 \mathrm{H}), 7.26(\mathrm{~d}, J=8.3 \mathrm{~Hz}, 1 \mathrm{H})$, $6.93(\mathrm{~d}, J=8.1 \mathrm{~Hz}, 1 \mathrm{H}), 4.98(\mathrm{~d}, J=2.4 \mathrm{~Hz}, 2 \mathrm{H}), 3.66(\mathrm{t}, J=2.4 \mathrm{~Hz}, 1 \mathrm{H}), 2.69(\mathrm{~s}, 3 \mathrm{H}) .{ }^{13} \mathrm{C}-\mathrm{NMR}(151 \mathrm{MHz}$, DMSO) $\delta$ 183.80, 165.88, 164.21, 155.27, 154.47, 146.86, 134.46, 132.67, 132.61, 130.01, 127.15, 118.69, 116.04, 115.90, 106.11, 105.87, 79.16, 56.62, 11.99. IR (KBr, cm $\left.{ }^{-1}\right): 3298,2925,2115,1642,1601,1501$, 1271, 1257, 1236, 1089. ESI-HRMS $(m / z)$ found: 331.0741 (calcd. for $\mathrm{C}_{19} \mathrm{H}_{13} \mathrm{FO}_{3} \mathrm{Na}[\mathrm{M}+\mathrm{Na}]^{+}:$331.0741).

2-(2,4-Difluorobenzoyl)-3-methyl-4-(propyn-3-yloxy)benzofuran (2b): Yellow solid; yield 55\%. ${ }^{1} \mathrm{H}-\mathrm{NMR}(600 \mathrm{MHz}$, DMSO- $\left.d_{6}\right) \delta 7.77(\mathrm{td}, J=8.3,6.5 \mathrm{~Hz}, 1 \mathrm{H}), 7.50-7.44(\mathrm{~m}, 2 \mathrm{H}), 7.28(\mathrm{td}, J=8.5,2.5 \mathrm{~Hz}, 1 \mathrm{H}), 7.20(\mathrm{~d}$, $J=8.4 \mathrm{~Hz}, 1 \mathrm{H}), 6.92(\mathrm{~d}, J=8.1 \mathrm{~Hz}, 1 \mathrm{H}), 4.98(\mathrm{~d}, J=2.4 \mathrm{~Hz}, 2 \mathrm{H}), 3.66(\mathrm{t}, J=2.4 \mathrm{~Hz}, 1 \mathrm{H}), 2.68(\mathrm{~s}, 3 \mathrm{H})$. ${ }^{13} \mathrm{C}-\mathrm{NMR}(151 \mathrm{MHz}, \mathrm{DMSO}) \delta 181.95,165.39,163.80,155.50,154.65,146.70,132.62,130.57,127.26$, 124.06, 118.80, 112.66, 112.50, 106.15, 105.79, 79.21, 56.66, 11.67. IR (KBr, cm $\left.{ }^{-1}\right)$ : 3239, 2116, 1641, 1612, 1499, 1086. ESI-HRMS $(m / z)$ found: 349.0646 (calcd. for $\mathrm{C}_{19} \mathrm{H}_{12} \mathrm{~F}_{2} \mathrm{O}_{3} \mathrm{Na}[\mathrm{M}+\mathrm{Na}]^{+}: 349.0647$ ).

\subsubsection{General Procedure for the Synthesis of Compounds $4 \mathbf{a}-\mathbf{r}$}

Compound 2a (305 mg, $1 \mathrm{mmol}), \mathrm{CuSO}_{4} \cdot 5 \mathrm{H}_{2} \mathrm{O}(50 \mathrm{mg}, 0.2 \mathrm{mmol})$ and 4-chloroazidobenzene (135 mg, $1 \mathrm{mmol}$ ) were dissolved in $10 \mathrm{~mL} \mathrm{DMF}$, and sodium ascorbate $(99 \mathrm{mg}, 0.5 \mathrm{mmol})$ was added. The reaction mixture was stirred at room temperature for $3 \mathrm{~h}$, then was poured into water. The crude product was filtered, which was purified by silica gel column chromatography (PET $/$ EtOAc $=2: 1$, $v / v)$ to give target compound $4 \mathrm{a}$ as yellow solid; yield $72 \%$; m.p.: $168-170{ }^{\circ} \mathrm{C} .{ }^{1} \mathrm{H}-\mathrm{NMR}(600 \mathrm{MHz}$, DMSO- $\left.d_{6}\right) \delta 9.02(\mathrm{~s}, 1 \mathrm{H}), 8.04(\mathrm{dd}, J=8.4,5.7 \mathrm{~Hz}, 2 \mathrm{H}), 7.96(\mathrm{~d}, J=8.7 \mathrm{~Hz}, 2 \mathrm{H}), 7.66(\mathrm{~d}, J=8.7 \mathrm{~Hz}, 2 \mathrm{H})$, $7.48(\mathrm{t}, J=8.2 \mathrm{~Hz}, 1 \mathrm{H}), 7.38(\mathrm{t}, J=8.7 \mathrm{~Hz}, 2 \mathrm{H}), 7.25(\mathrm{~d}, J=8.4 \mathrm{~Hz}, 1 \mathrm{H}), 7.09(\mathrm{~d}, J=8.1 \mathrm{~Hz}, 1 \mathrm{H}), 5.41(\mathrm{~s}$, 2H), 2.65 (s, 3H); ${ }^{13}$ C-NMR (101 MHz, DMSO) $\delta 183.85,155.41,155.32,146.88,144.22,135.77,133.55$, 
132.76, 132.66, 130.35, 130.32, 127.51, 123.33, 122.31, 118.74, 116.17, 115.95, 106.08, 105.78, 62.24, 12.13; IR (KBr, cm $\left.{ }^{-1}\right):$ 2925, 1635, 1599, 1553, 1502, 1271, 1252, 1087. ESI-HRMS (m/z) found: 484.0841 (calcd. for $\mathrm{C}_{25} \mathrm{H}_{17} \mathrm{ClFN}_{3} \mathrm{O}_{3} \mathrm{Na}[\mathrm{M}+\mathrm{Na}]^{+}$: 484.0835).

The compounds $\mathbf{4 b}-\mathbf{r}$ were synthesized using the same operation procedure of compound $\mathbf{4 a}$.

Compound 4b: Yellow solid; yield 79\%; m.p.: $169-170{ }^{\circ} \mathrm{C} .{ }^{1} \mathrm{H}-\mathrm{NMR}\left(600 \mathrm{MHz}, \mathrm{DMSO}-d_{6}\right) \delta 8.78(\mathrm{~s}, 1 \mathrm{H})$, 8.07-8.02 (m, 2H), $7.78(\mathrm{dd}, J=8.0,1.4 \mathrm{~Hz}, 1 \mathrm{H}), 7.73(\mathrm{dd}, J=7.8,1.7 \mathrm{~Hz}, 1 \mathrm{H}), 7.64(\mathrm{td}, J=7.8,1.7 \mathrm{~Hz}$, $1 \mathrm{H}), 7.59(\mathrm{td}, J=7.7,1.4 \mathrm{~Hz}, 1 \mathrm{H}), 7.50(\mathrm{t}, J=8.2 \mathrm{~Hz}, 1 \mathrm{H}), 7.40(\mathrm{t}, J=8.8 \mathrm{~Hz}, 2 \mathrm{H}), 7.26(\mathrm{~d}, J=8.4 \mathrm{~Hz}, 1 \mathrm{H})$, $7.12(\mathrm{~d}, J=8.1 \mathrm{~Hz}, 1 \mathrm{H}), 5.44$ (s, 2H), 2.65 (s, 3H). ${ }^{13} \mathrm{C}-\mathrm{NMR}(101 \mathrm{MHz}, \mathrm{DMSO}) \delta 183.88,155.41,146.90$, 143.10, 134.90, 134.59, 132.76, 132.67, 132.22, 131.04, 130.33, 129.00, 128.90, 127.50, 127.28, 118.78, 116.18, 115.96, 106.24, 105.79, 62.37, 12.06. IR (KBr, cm $\left.{ }^{-1}\right):$ 2923, 1638, 1598, 1556, 1500, 1272, $121232,1091$. ESI-HRMS $(m / z)$ found: 484.0844 (calcd. for $\mathrm{C}_{25} \mathrm{H}_{17} \mathrm{ClFN}_{3} \mathrm{O}_{3} \mathrm{Na}[\mathrm{M}+\mathrm{Na}]^{+}:$484.0835).

Compound 4c: Yellow solid; yield 76\%; m.p.: $172-174{ }^{\circ} \mathrm{C} .{ }^{1} \mathrm{H}-\mathrm{NMR}\left(600 \mathrm{MHz}, \mathrm{DMSO}-d_{6}\right) \delta 9.04(\mathrm{~s}$, $1 \mathrm{H}), 8.04(\mathrm{dd}, J=8.5,5.6 \mathrm{~Hz}, 2 \mathrm{H}), 7.90(\mathrm{~d}, J=8.8 \mathrm{~Hz}, 2 \mathrm{H}), 7.80(\mathrm{~d}, J=8.8 \mathrm{~Hz}, 2 \mathrm{H}), 7.49(\mathrm{t}, J=8.2 \mathrm{~Hz}$, $1 \mathrm{H}), 7.39(\mathrm{t}, J=8.8 \mathrm{~Hz}, 2 \mathrm{H}), 7.25(\mathrm{~d}, J=8.4 \mathrm{~Hz}, 1 \mathrm{H}), 7.10(\mathrm{~d}, J=8.0 \mathrm{~Hz}, 1 \mathrm{H}), 5.42(\mathrm{~s}, 2 \mathrm{H}), 2.65(\mathrm{~s}$, 3H). ${ }^{13} \mathrm{C}-\mathrm{NMR}(101 \mathrm{MHz}, \mathrm{DMSO}) \delta$ 183.87, 155.32, 146.88, 144.23, 136.18, 133.28, 132.76, 132.67, 130.33, 127.51, 123.31, 122.55, 121.93, 118.74, 116.17, 115.96, 106.09, 105.79, 62.24, 40.61, 12.14. IR (KBr, $\mathrm{cm}^{-1}$ ): 2924, 1633, 1600, 1550, 1498, 1270, 1251, 1087. ESI-HRMS ( $\left.\mathrm{m} / z\right)$ found: 506.0515 (calcd. for $\mathrm{C}_{25} \mathrm{H}_{18} \mathrm{BrFN}_{3} \mathrm{O}_{3}[\mathrm{M}+\mathrm{H}]^{+}:$506.0516).

Compound 4d: Yellow solid; yield 81\%; m.p.: $166-169{ }^{\circ} \mathrm{C} .{ }^{1} \mathrm{H}-\mathrm{NMR}\left(600 \mathrm{MHz}, \mathrm{DMSO}-d_{6}\right) \delta 8.75(\mathrm{~s}$, $1 \mathrm{H}), 8.05(\mathrm{dd}, J=8.6,5.6 \mathrm{~Hz}, 2 \mathrm{H}), 7.93-7.90(\mathrm{~m}, 1 \mathrm{H}), 7.68(\mathrm{dd}, J=7.8,1.3 \mathrm{~Hz}, 1 \mathrm{H}), 7.64-7.61(\mathrm{~m}, 1 \mathrm{H})$, $7.58-7.54(\mathrm{~m}, 1 \mathrm{H}), 7.50(\mathrm{t}, J=8.2 \mathrm{~Hz}, 1 \mathrm{H}), 7.40(\mathrm{t}, J=8.8 \mathrm{~Hz}, 2 \mathrm{H}), 7.26(\mathrm{~d}, J=8.3 \mathrm{~Hz}, 1 \mathrm{H}), 7.12(\mathrm{~d}$, $J=8.1 \mathrm{~Hz}, 1 \mathrm{H}), 5.44$ (s, 2H), 2.66 (s, 3H). ${ }^{13} \mathrm{C}-\mathrm{NMR}(101 \mathrm{MHz}, \mathrm{DMSO}) \delta 183.87,155.40,146.89,143.02$, $136.58,134.58,134.11,132.76,132.67,132.52,130.33,129.46,129.20,127.53,127.25,119.34,118.78,116.17$, 115.95, 106.23, 105.77, 62.40, 12.09. IR (KBr, cm $\left.{ }^{-1}\right):$ 2923, 1638, 1614, 1598, 1555, 1500, 1271, 1255, 1090. ESI-HRMS $(m / z)$ found: 506.0520 (calcd. for $\mathrm{C}_{25} \mathrm{H}_{18} \mathrm{BrFN}_{3} \mathrm{O}_{3}[\mathrm{M}+\mathrm{H}]^{+}:$506.0516).

Compound 4e: Yellow solid; yield 77\%; m.p.: $160-161{ }^{\circ} \mathrm{C} .{ }^{1} \mathrm{H}-\mathrm{NMR}\left(600 \mathrm{MHz}, \mathrm{DMSO}-d_{6}\right) \delta 8.96(\mathrm{~s}$, $1 \mathrm{H}), 8.04(\mathrm{dd}, J=8.7,5.6 \mathrm{~Hz}, 2 \mathrm{H}), 7.80(\mathrm{~d}, J=8.4 \mathrm{~Hz}, 2 \mathrm{H}), 7.49(\mathrm{t}, J=8.2 \mathrm{~Hz}, 1 \mathrm{H}), 7.39(\mathrm{~m}, J=8.8$, $4.7 \mathrm{~Hz}, 4 \mathrm{H}), 7.25(\mathrm{~d}, J=8.4 \mathrm{~Hz}, 1 \mathrm{H}), 7.10(\mathrm{~d}, J=8.1 \mathrm{~Hz}, 1 \mathrm{H}), 5.41(\mathrm{~s}, 2 \mathrm{H}), 2.66(\mathrm{~s}, 3 \mathrm{H}), 2.37(\mathrm{~s}, 3 \mathrm{H})$. ${ }^{13} \mathrm{C}-\mathrm{NMR}(101 \mathrm{MHz}, \mathrm{DMSO}) \delta 183.85,155.36,146.87,143.91,138.90,134.74,134.55,132.75,132.66$, $130.71,130.32,127.53,123.12,120.47,118.73,116.16,115.94,106.07,105.74,62.30,21.05,12.13$. IR $(\mathrm{KBr}$, $\mathrm{cm}^{-1}$ ): 2925, 1637, 1599, 1553, 1499, 1271, 1254, 1088. ESI-HRMS ( $\mathrm{m} / z$ ) found: 464.1393 (calcd. for $\mathrm{C}_{26} \mathrm{H}_{20} \mathrm{FN}_{3} \mathrm{O}_{3} \mathrm{Na}[\mathrm{M}+\mathrm{Na}]^{+}:$464.1386).

Compound 4f: Yellow solid; yield 80\%; m.p.: $154-156{ }^{\circ} \mathrm{C} .{ }^{1} \mathrm{H}-\mathrm{NMR}\left(600 \mathrm{MHz}, \mathrm{DMSO}-d_{6}\right) \delta 8.69(\mathrm{~s}, 1 \mathrm{H})$, 8.10-7.99 (m, 2H), 7.51-7.45 (m, 4H), $7.40(\mathrm{q}, J=8.7 \mathrm{~Hz}, 3 \mathrm{H}), 7.26(\mathrm{~d}, J=8.5 \mathrm{~Hz}, 1 \mathrm{H}), 7.12(\mathrm{~d}, J=8.1 \mathrm{~Hz}$, 1H), 5.43 (s, 2H), 2.65 (s, 3H), 2.13 (s, 3H). ${ }^{13} \mathrm{C}-\mathrm{NMR}(101 \mathrm{MHz}, \mathrm{DMSO}) \delta 183.87,166.37,163.87,155.41$, 146.88, 143.08, 136.66, 134.55, 133.54, 132.76, 132.67, 131.84, 130.34, 127.50, 126.66, 126.52, 118.77, 116.17, $115.95,106.18,105.75,62.50,17.78,12.04 . \mathrm{IR}\left(\mathrm{KBr}, \mathrm{cm}^{-1}\right): 2925,1639,1624,1599,1544,1501,1271,1250$, 1234, 1089. ESI-HRMS ( $m / z$ ) found: 464.1394 (calcd. for $\mathrm{C}_{26} \mathrm{H}_{20} \mathrm{FN}_{3} \mathrm{O}_{3} \mathrm{Na}[\mathrm{M}+\mathrm{Na}]^{+}: 464.1386$ ).

Compound 4g: Yellow solid; yield 78\%; m.p.: $155-158^{\circ} \mathrm{C} .{ }^{1} \mathrm{H}-\mathrm{NMR}\left(600 \mathrm{MHz}, \mathrm{DMSO}-d_{6}\right) \delta 8.67(\mathrm{~s}, 1 \mathrm{H})$, $8.04(\mathrm{dd}, J=8.8,5.6 \mathrm{~Hz} 2 \mathrm{H}), 7.54(\mathrm{~m}, 1 \mathrm{H}), 7.51-7.47(\mathrm{~m}, 2 \mathrm{H}), 7.42(\mathrm{dd}, J=4.3,1.5 \mathrm{~Hz}, 2 \mathrm{H}), 7.41-7.35$ $(\mathrm{m}, 2 \mathrm{H}), 7.26(\mathrm{~d}, J=8.3 \mathrm{~Hz}, 1 \mathrm{H}), 7.11(\mathrm{~d}, J=8.1 \mathrm{~Hz}, 1 \mathrm{H}), 5.43(\mathrm{~s}, 2 \mathrm{H}), 2.64(\mathrm{~s}, 3 \mathrm{H}), 2.41(\mathrm{q}, J=7.6 \mathrm{~Hz}$, 2H), 0.96 (t, $J=7.6 \mathrm{~Hz}, 3 \mathrm{H}) .{ }^{13} \mathrm{C}-\mathrm{NMR}(101 \mathrm{MHz}, \mathrm{DMSO}) \delta 183.86,166.37,163.88,155.40,146.90$, 143.11, 139.81, 136.13, 134.58, 132.76, 132.66, 130.75, 130.38, 130.31, 127.49, 126.96, 118.80, 116.17, 115.95, 106.24, 105.74, 62.50, 24.27, 15.17, 11.99. IR (KBr, cm $\left.{ }^{-1}\right):$ 2925, 1626, 1598, 1541, 1501, 1269, $1249,1088$. ESI-HRMS ( $m / z$ ) found: 456.1719 (calcd. for $\mathrm{C}_{27} \mathrm{H}_{23} \mathrm{FN}_{3} \mathrm{O}_{3}[\mathrm{M}+\mathrm{H}]^{+}:$456.1723). 
Compound 4h: Yellow solid; yield 71\%; m.p.: $156-159{ }^{\circ} \mathrm{C} .{ }^{1} \mathrm{H}-\mathrm{NMR}\left(600 \mathrm{MHz}\right.$, DMSO- $\left.d_{6}\right) \delta 8.58(\mathrm{~s}, 1 \mathrm{H})$, $8.04(\mathrm{dd}, J=8.7,5.6 \mathrm{~Hz}, 2 \mathrm{H}), 7.49(\mathrm{t}, J=8.2 \mathrm{~Hz}, 1 \mathrm{H}), 7.45-7.34(\mathrm{~m}, 3 \mathrm{H}), 7.29(\mathrm{~d}, J=7.6 \mathrm{~Hz}, 2 \mathrm{H}), 7.25(\mathrm{~d}$, $J=8.4 \mathrm{~Hz}, 1 \mathrm{H}), 7.09(\mathrm{~d}, J=8.0 \mathrm{~Hz}, 1 \mathrm{H}), 5.44(\mathrm{~s}, 2 \mathrm{H}), 2.62(\mathrm{~s}, 3 \mathrm{H}), 1.91(\mathrm{~s}, 6 \mathrm{H}) .{ }^{13} \mathrm{C}-\mathrm{NMR}(101 \mathrm{MHz}$, DMSO) $\delta 183.86,155.39,146.90,143.12,136.22,135.30,134.57,132.76,132.67,130.48,130.30,128.87$, 127.46, 126.98, 118.80, 116.17, 115.95, 106.28, 105.74, 62.65, 17.24, 11.88. IR (KBr, cm $\left.{ }^{-1}\right): 2924,1640$, $1599,1551,1501,1271,1255,1101,1042$. ESI-HRMS $(m / z)$ found: 456.1716 (calcd. for $\mathrm{C}_{27} \mathrm{H}_{23} \mathrm{FN}_{3} \mathrm{O}_{3}$ $\left.[\mathrm{M}+\mathrm{H}]^{+}: 456.1723\right)$.

Compound 4i: Yellow solid; yield 70\%; m.p.: $157-158^{\circ} \mathrm{C} .{ }^{1} \mathrm{H}-\mathrm{NMR}\left(600 \mathrm{MHz}, \mathrm{DMSO}-d_{6}\right) \delta 8.63(\mathrm{~s}, 1 \mathrm{H})$, $8.04(\mathrm{dd}, J=8.7,5.6 \mathrm{~Hz}, 2 \mathrm{H}), 7.49(\mathrm{t}, J=8.2 \mathrm{~Hz}, 1 \mathrm{H}), 7.43-7.36(\mathrm{~m}, 2 \mathrm{H}), 7.33(\mathrm{~d}, J=8.0 \mathrm{~Hz}, 1 \mathrm{H}), 7.28(\mathrm{~d}$, $J=1.8 \mathrm{~Hz}, 1 \mathrm{H}), 7.26(\mathrm{~d}, J=8.4 \mathrm{~Hz}, 1 \mathrm{H}), 7.20(\mathrm{dd}, J=8.0,1.9 \mathrm{~Hz}, 1 \mathrm{H}), 7.11(\mathrm{~d}, J=8.1 \mathrm{~Hz}, 1 \mathrm{H}), 5.42(\mathrm{~s}$, 2H), $2.65(\mathrm{~s}, 3 \mathrm{H}), 2.35$ (s, 3H), $2.08(\mathrm{~s}, 3 \mathrm{H}) .{ }^{13} \mathrm{C}-\mathrm{NMR}(101 \mathrm{MHz}, \mathrm{DMSO}) \delta 183.85,163.87,155.42,146.88$, $142.99,140.02$, 134.57, 134.29, 133.19, 132.76, 132.66, 132.23, 130.32, 127.89, 127.51, 126.66, 126.30, 118.77, 116.17, 115.95, 106.17, 105.73, 62.50, 21.10, 17.68, 12.03. IR (KBr, $\left.\mathrm{cm}^{-1}\right): 2925,1639,1600,1553,1502$, 1270, 1255, 1101. ESI-HRMS ( $m / z$ ) found: 456.1713 (calcd. for $\mathrm{C}_{27} \mathrm{H}_{23} \mathrm{FN}_{3} \mathrm{O}_{3}[\mathrm{M}+\mathrm{H}]^{+}:$456.1723).

Compound 4j: Yellow solid; yield 82\%; m.p.: $168-171{ }^{\circ} \mathrm{C} .{ }^{1} \mathrm{H}-\mathrm{NMR}\left(600 \mathrm{MHz}, \mathrm{DMSO}-d_{6}\right) \delta 9.04(\mathrm{~s}, 1 \mathrm{H})$, $7.99-7.94(\mathrm{~m}, 2 \mathrm{H}), 7.75(\mathrm{td}, J=8.4,6.5 \mathrm{~Hz}, 1 \mathrm{H}), 7.69-7.64(\mathrm{~m}, 2 \mathrm{H}), 7.49(\mathrm{t}, J=8.2 \mathrm{~Hz}, 1 \mathrm{H}), 7.45(\mathrm{td}$, $J=10.3,2.3 \mathrm{~Hz}, 1 \mathrm{H}), 7.27(\mathrm{td}, J=8.4,2.2 \mathrm{~Hz}, 1 \mathrm{H}), 7.20(\mathrm{~d}, J=8.4 \mathrm{~Hz}, 1 \mathrm{H}), 7.09(\mathrm{~d}, J=8.1 \mathrm{~Hz}, 1 \mathrm{H}), 5.42(\mathrm{~s}$, 2H), 2.64 (s, 3H). ${ }^{13} \mathrm{C}-\mathrm{NMR}(101 \mathrm{MHz}, \mathrm{DMSO}) \delta 182.80,156.45,15631,147.55,144.98,136.58,134.35$, 133.46, 131.68, 131.16, 128.44, 124.15, 123.12, 119.66, 113.39, 106.91, 106.50, 106.35, 106.09, 105.83, 63.08, 12.62. IR (KBr, cm $\left.{ }^{-1}\right)$ : 2924, 1635, 1600, 1551, 1502, 1271, 1252, 1088. ESI-HRMS $(\mathrm{m} / \mathrm{z})$ found: 480.0917 (calcd. for $\mathrm{C}_{25} \mathrm{H}_{17} \mathrm{ClF}_{2} \mathrm{~N}_{3} \mathrm{O}_{3}[\mathrm{M}+\mathrm{H}]^{+}$: 480.0927).

Compound 4k: Yellow solid; yield 78\%; m.p.: $166-168{ }^{\circ} \mathrm{C} .{ }^{1} \mathrm{H}-\mathrm{NMR}\left(600 \mathrm{MHz}, \mathrm{DMSO}-d_{6}\right) \delta 8.78(\mathrm{~s}, 1 \mathrm{H})$, $7.80-7.75(\mathrm{~m}, 2 \mathrm{H}), 7.73(\mathrm{dd}, J=7.8,1.7 \mathrm{~Hz}, 1 \mathrm{H}), 7.64(\mathrm{td}, J=7.8,1.6 \mathrm{~Hz}, 1 \mathrm{H}), 7.59(\mathrm{t}, J=7.6 \mathrm{~Hz}, 1 \mathrm{H}), 7.50$ $(\mathrm{t}, J=8.2 \mathrm{~Hz}, 1 \mathrm{H}), 7.46(\mathrm{td}, J=10.3,2.2 \mathrm{~Hz}, 1 \mathrm{H}), 7.27(\mathrm{td}, J=8.5,2.2 \mathrm{~Hz}, 1 \mathrm{H}), 7.21(\mathrm{~d}, J=8.4 \mathrm{~Hz}, 1 \mathrm{H})$, $7.12(\mathrm{~d}, J=8.1 \mathrm{~Hz}, 1 \mathrm{H}), 5.45(\mathrm{~s}, 2 \mathrm{H}), 2.63(\mathrm{~s}, 3 \mathrm{H}) .{ }^{13} \mathrm{C}-\mathrm{NMR}(101 \mathrm{MHz}, \mathrm{DMSO}) \delta 181.99,155.64,155.56$, $146.75,143.06,134.89,132.22,131.03,130.88,129.01,128.98,128.90,127.62,127.28,118.90,112.79,112.57$, 106.27, 105.70, 105.55, 105.29, 105.03, 62.41, 11.73. IR (KBr, $\left.\mathrm{cm}^{-1}\right)$ : 2923, 1642, 1613, 1560, 1497, 1268, 1091. ESI-HRMS ( $m / z$ ) found: 480.0923 (calcd. for $\mathrm{C}_{25} \mathrm{H}_{17} \mathrm{ClF}_{2} \mathrm{~N}_{3} \mathrm{O}_{3}[\mathrm{M}+\mathrm{H}]^{+}: 480.0927$ ).

Compound 41: Yellow solid; yield 78\%; m.p.: $167-170{ }^{\circ} \mathrm{C} .{ }^{1} \mathrm{H}-\mathrm{NMR}\left(600 \mathrm{MHz}, \mathrm{DMSO}-d_{6}\right) \delta 9.03(\mathrm{~s}, 1 \mathrm{H})$, $7.90(\mathrm{~d}, J=8.4 \mathrm{~Hz}, 2 \mathrm{H}), 7.81(\mathrm{~d}, J=8.4 \mathrm{~Hz}, 2 \mathrm{H}), 7.75(\mathrm{q}, J=7.8 \mathrm{~Hz}, 1 \mathrm{H}), 7.49(\mathrm{t}, J=8.3 \mathrm{~Hz}, 1 \mathrm{H}), 7.45(\mathrm{t}$, $J=9.5 \mathrm{~Hz}, 1 \mathrm{H}), 7.31-7.23(\mathrm{~m}, 1 \mathrm{H}), 7.20(\mathrm{~d}, J=8.4 \mathrm{~Hz}, 1 \mathrm{H}), 7.10(\mathrm{~d}, J=8.1 \mathrm{~Hz}, 1 \mathrm{H}), 5.42(\mathrm{~s}, 2 \mathrm{H}), 2.64(\mathrm{~s}$, 3H). ${ }^{13} \mathrm{C}-\mathrm{NMR}(101 \mathrm{MHz}$, DMSO) $\delta 181.99,155.64,155.50,146.74,144.20,136.18,133.27,130.87,127.63$, $123.29,122.55,121.93,118.85,112.79,112.56,106.12,105.70,105.55,105.28,105.02,62.28,11.81$. IR (KBr, $\left.\mathrm{cm}^{-1}\right): 2925,1648,1612,1565,1498,1270,1254,1085$. ESI-HRMS $(\mathrm{m} / z)$ found: 546.0235 (calcd. for $\mathrm{C}_{25} \mathrm{H}_{16} \mathrm{BrF}_{2} \mathrm{~N}_{3} \mathrm{O}_{3} \mathrm{Na}[\mathrm{M}+\mathrm{Na}]^{+}:$546.0235).

Compound 4m: Yellow solid; yield 80\%; m.p.: $166-169{ }^{\circ} \mathrm{C} .{ }^{1} \mathrm{H}-\mathrm{NMR}\left(600 \mathrm{MHz}, \mathrm{DMSO}-d_{6}\right) \delta 8.74(\mathrm{~s}, 1 \mathrm{H})$, $7.92(\mathrm{~d}, J=8.0 \mathrm{~Hz}, 1 \mathrm{H}), 7.79-7.73(\mathrm{~m}, 1 \mathrm{H}), 7.68(\mathrm{dd}, J=7.8,1.6 \mathrm{~Hz}, 1 \mathrm{H}), 7.62(\mathrm{t}, J=7.6 \mathrm{~Hz}, 1 \mathrm{H}), 7.56(\mathrm{t}$, $J=7.7 \mathrm{~Hz}, 1 \mathrm{H}), 7.50(\mathrm{t}, J=8.2 \mathrm{~Hz}, 1 \mathrm{H}), 7.45(\mathrm{td}, J=10.0,2.4 \mathrm{~Hz}, 1 \mathrm{H}), 7.27(\mathrm{td}, J=8.5,2.4 \mathrm{~Hz}, 1 \mathrm{H}), 7.20$ $(\mathrm{d}, J=8.4 \mathrm{~Hz}, 1 \mathrm{H}), 7.12(\mathrm{~d}, J=8.1 \mathrm{~Hz}, 1 \mathrm{H}), 5.45(\mathrm{~s}, 2 \mathrm{H}), 2.64(\mathrm{~s}, 3 \mathrm{H}) .{ }^{13} \mathrm{C}-\mathrm{NMR}(101 \mathrm{MHz}, \mathrm{DMSO}) \delta$ $181.99,162.75,155.57,146.75,142.98,136.58,134.11,132.52,130.89,129.46,129.20,127.65,127.26,119.35$, 118.90, 112.78, 112.57, 106.27, 105.69, 105.55, 105.29, 105.02, 62.44, 11.76. IR $\left(\mathrm{KBr}^{\mathrm{c}} \mathrm{cm}^{-1}\right)$ : 2924, 1645, $1613,1597,1560,1266,1253,1086$. ESI-HRMS $(m / z)$ found: 546.0238 (calcd. for $\mathrm{C}_{25} \mathrm{H}_{16} \mathrm{BrF}_{2} \mathrm{~N}_{3} \mathrm{O}_{3} \mathrm{Na}$ $[\mathrm{M}+\mathrm{Na}]^{+}:$546.0235). 
Compound 4n: Yellow solid; yield 78\%; m.p.: $164-166{ }^{\circ} \mathrm{C} .{ }^{1} \mathrm{H}-\mathrm{NMR}\left(600 \mathrm{MHz}, \mathrm{DMSO}-d_{6}\right) \delta 8.95$ (s, $1 \mathrm{H}), 7.79(\mathrm{~d}, J=8.4 \mathrm{~Hz}, 2 \mathrm{H}), 7.75(\mathrm{~m}, J=8.3 \mathrm{~Hz}, 1 \mathrm{H}), 7.49(\mathrm{t}, J=8.2 \mathrm{~Hz}, 1 \mathrm{H}), 7.45(\mathrm{td}, J=10.4$, $2.3 \mathrm{~Hz}, 1 \mathrm{H}), 7.39(\mathrm{~d}, J=8.1 \mathrm{~Hz}, 2 \mathrm{H}), 7.27(\mathrm{td}, J=8.5,2.5 \mathrm{~Hz}, 1 \mathrm{H}), 7.19(\mathrm{~d}, J=8.4 \mathrm{~Hz}, 1 \mathrm{H}), 7.10(\mathrm{~d}$, $J=8.1 \mathrm{~Hz}, 1 \mathrm{H}), 5.41(\mathrm{~s}, 2 \mathrm{H}), 2.64(\mathrm{~s}, 3 \mathrm{H}), 2.37$ (s, 3H). ${ }^{13} \mathrm{C}-\mathrm{NMR}(101 \mathrm{MHz}, \mathrm{DMSO}) \delta 181.98,155.64$, $155.54,146.73,143.88,138.90,134.74,132.55,130.87,130.71,127.64,123.12,120.48,118.85,112.76$, $112.55,106.10,105.65,105.28,105.02,62.34,21.04,11.80$. IR $\left(\mathrm{KBr}, \mathrm{cm}^{-1}\right): 2325,1649,1612,1564$, 1498, 1271, 1256, 1086. ESI-HRMS ( $m / z$ ) found: 460.1466 (calcd. for $\mathrm{C}_{26} \mathrm{H}_{20} \mathrm{~F}_{2} \mathrm{~N}_{3} \mathrm{O}_{3}[\mathrm{M}+\mathrm{H}]^{+}: 460.1473$ ).

Compound 4o: Yellow solid; yield 75\%; m.p.: $165-168{ }^{\circ} \mathrm{C} .{ }^{1} \mathrm{H}-\mathrm{NMR}\left(600 \mathrm{MHz}, \mathrm{DMSO}-d_{6}\right) \delta 8.69$ (s, $1 \mathrm{H}), 7.94(\mathrm{~s}, 1 \mathrm{H}), 7.76(\mathrm{td}, J=8.3,6.5 \mathrm{~Hz}, 1 \mathrm{H}), 7.51-7.40(\mathrm{~m}, 5 \mathrm{H}) 7.27(\mathrm{td}, J=8.5,2.5 \mathrm{~Hz}, 1 \mathrm{H}), 7.20(\mathrm{~d}$, $J=8.4 \mathrm{~Hz}, 1 \mathrm{H}), 7.11(\mathrm{~d}, J=8.1 \mathrm{~Hz}, 1 \mathrm{H}), 5.43(\mathrm{~s}, 2 \mathrm{H}), 2.64(\mathrm{~s}, 3 \mathrm{H}), 2.13(\mathrm{~s}, 3 \mathrm{H}) .{ }^{13} \mathrm{C}-\mathrm{NMR}(101 \mathrm{MHz}$, DMSO) $\delta 181.99,162.75,155.64,155.59,146.75,143.04,136.65,133.54,132.67,131.83,130.88,130.37$, $127.63,127.50,126.66,126.52,118.89,112.77,112.57,106.22,105.66,105.29,62.54,17.77,11.71$. IR (KBr, $\left.\mathrm{cm}^{-1}\right)$ : 2924, 1641, 1610, 1563, 1500, 1269, 1090, 1039. ESI-HRMS $(\mathrm{m} / \mathrm{z})$ found: 460.1468 (calcd. for $\mathrm{C}_{26} \mathrm{H}_{20} \mathrm{~F}_{2} \mathrm{~N}_{3} \mathrm{O}_{3}[\mathrm{M}+\mathrm{H}]^{+}:$460.1473).

Compound 4p: Yellow solid; yield 85\%; m.p.: $168-170{ }^{\circ} \mathrm{C} .{ }^{1} \mathrm{H}-\mathrm{NMR}\left(600 \mathrm{MHz}, \mathrm{DMSO}-d_{6}\right) \delta 8.67(\mathrm{~s}, 1 \mathrm{H})$, $7.75(\mathrm{td}, J=8.3,6.5 \mathrm{~Hz}, 1 \mathrm{H}), 7.54(\mathrm{td}, J=5.4,5.0,2.3 \mathrm{~Hz}, 1 \mathrm{H}), 7.51-7.48(\mathrm{~m}, 2 \mathrm{H}), 7.47-7.43(\mathrm{~m}, 1 \mathrm{H}), 7.42$ $(\mathrm{dd}, J=3.8,1.2 \mathrm{~Hz}, 2 \mathrm{H}), 7.27(\mathrm{td}, J=8.5,2.5 \mathrm{~Hz}, 1 \mathrm{H}), 7.20(\mathrm{~d}, J=8.4 \mathrm{~Hz}, 1 \mathrm{H}), 7.11(\mathrm{~d}, J=8.1 \mathrm{~Hz}, 1 \mathrm{H})$, $5.43(\mathrm{~s}, 2 \mathrm{H}), 2.63(\mathrm{~s}, 3 \mathrm{H}), 2.40(\mathrm{q}, J=7.6 \mathrm{~Hz}, 2 \mathrm{H}), 0.95(\mathrm{t}, J=7.6 \mathrm{~Hz}, 3 \mathrm{H}) .{ }^{13} \mathrm{C}-\mathrm{NMR}(101 \mathrm{MHz}, \mathrm{DMSO}) \delta$ 182.00, 155.63, 155.56, 146.74, 143.06, 139.80, 136.12, 130.87, 130.74, 130.37, 127.61, 127.48, 126.98, 126.94, 118.91, 112.76, 112.55, 106.28, 105.66, 105.53, 105.28, 105.02, 62.53, 24.26, 15.16, 11.66. IR $\left(\mathrm{KBr}_{\mathrm{cm}}^{-1}\right)$ : 2930, 1644, 1611, 1562, 1499, 1270, 1090. ESI-HRMS ( $m / z$ ) found: 496.1453 (calcd. for $\mathrm{C}_{27} \mathrm{H}_{21} \mathrm{~F}_{2} \mathrm{~N}_{3} \mathrm{O}_{3} \mathrm{Na}$ $[\mathrm{M}+\mathrm{H}]^{+}:$496.1443).

Compound 4q: Yellow solid; yield 79\%; m.p.: $165-168{ }^{\circ} \mathrm{C} .{ }^{1} \mathrm{H}-\mathrm{NMR}\left(600 \mathrm{MHz}, \mathrm{DMSO}-d_{6}\right) \delta 8.58$ (s, 1H), 7.79-7.72 (m, 1H), $7.49(\mathrm{t}, J=8.2 \mathrm{~Hz}, 1 \mathrm{H}), 7.47-7.43(\mathrm{~m}, 1 \mathrm{H}), 7.39(\mathrm{t}, J=7.6 \mathrm{~Hz}, 1 \mathrm{H}), 7.30-7.25$ $(\mathrm{m}, 3 \mathrm{H}), 7.20(\mathrm{~d}, J=8.4 \mathrm{~Hz}, 1 \mathrm{H}), 7.09(\mathrm{~d}, J=8.0 \mathrm{~Hz}, 1 \mathrm{H}), 5.44(\mathrm{~s}, 2 \mathrm{H}), 2.61(\mathrm{~s}, 3 \mathrm{H}), 1.90(\mathrm{~s}, 6 \mathrm{H})$. ${ }^{13} \mathrm{C}-\mathrm{NMR}(101 \mathrm{MHz}, \mathrm{DMSO}) \delta 181.99,159.32,155.59,146.76,143.09,136.21,135.30,130.85,130.48$, $128.87,127.57,126.97,118.93,112.78,112.58,106.34,105.66,105.54,105.28,105.03,62.70,17.24,11.55$. IR (KBr, cm $\left.{ }^{-1}\right)$ : 2924, 1643, 1610, 1559, 1498, 1268, 1090. ESI-HRMS ( $\left.m / z\right)$ found: 474.1613 (calcd. for $\mathrm{C}_{27} \mathrm{H}_{22} \mathrm{~F}_{2} \mathrm{~N}_{3} \mathrm{O}_{3}[\mathrm{M}+\mathrm{H}]^{+}$: 474.1629).

Compound 4r: Yellow solid; yield 79\%; m.p.: $169-171^{\circ} \mathrm{C} .{ }^{1} \mathrm{H}-\mathrm{NMR}\left(600 \mathrm{MHz}, \mathrm{DMSO}-d_{6}\right) \delta 8.62(\mathrm{~s}, 1 \mathrm{H})$, $7.75(\mathrm{q}, J=8.2 \mathrm{~Hz}, 1 \mathrm{H}), 7.49(\mathrm{t}, J=8.2 \mathrm{~Hz}, 1 \mathrm{H}), 7.47-7.42(\mathrm{~m}, 1 \mathrm{H}), 7.32(\mathrm{~d}, J=8.0 \mathrm{~Hz}, 1 \mathrm{H}), 7.28(\mathrm{~s}, 2 \mathrm{H}), 7.20$ $(\mathrm{m}, 2 \mathrm{H}), 7.11(\mathrm{~d}, J=8.1 \mathrm{~Hz}, 1 \mathrm{H}), 5.42(\mathrm{~s}, 2 \mathrm{H}), 2.63(\mathrm{~s}, 3 \mathrm{H}), 2.35(\mathrm{~s}, 3 \mathrm{H}), 2.08(\mathrm{~s}, 3 \mathrm{H}) .{ }^{13} \mathrm{C}-\mathrm{NMR}(101 \mathrm{MHz}$, DMSO) $\delta 181.99,155.62,146.74,142.95,140.02,134.28,133.18,132.55,132.23,130.88,127.89,127.63$, $126.67,126.30,118.89,112.78,112.56,106.22,105.65,105.54,105.28,105.02,62.54,21.10,17.67,11.70$. IR (KBr, cm $\left.{ }^{-1}\right)$ : 2925, 1643, 1611, 1563, 1499, 1269, 1090. ESI-HRMS ( $\left.m / z\right)$ found: 474.1623 (calcd. for $\mathrm{C}_{27} \mathrm{H}_{22} \mathrm{~F}_{2} \mathrm{~N}_{3} \mathrm{O}_{3}[\mathrm{M}+\mathrm{H}]^{+}:$474.1629).

\subsection{Antifungal Assay}

Test fungal strains were obtained from China Pharmaceutical Culture Collection (Candida albicans CPCC400616), China General Microbiological Culture Collection Center (Cryptococcus neoformans CGMCC2.3161 and Candida zeylanoides CGMCC2.3739) or were clinical isolates (Trichophyton rubrum and Rhodotorula rubra).

The in vitro antifungal activity of target compounds was determined by the micro-broth dilution method in 96-well plates according to the CLSI M27-A3 guidelines [35]. Tested compounds and the control drug were dissolved in DMSO respectively and Tween-20 was added as a stabilizer. 
The prepared samples were serially two-fold diluted in growth medium, inoculated and incubated at $35^{\circ} \mathrm{C}$. The MICs were determined at $24 \mathrm{~h}$ for C. alb., C. zey., T. rub., and R. rub., and at $72 \mathrm{~h}$ for C. neo.

\section{Conclusions}

In summary, a series of benzofuran-triazoles hybrids has been designed and synthesized. The target compounds were characterized by HRMS, FTIR and NMR. The biological assay results indicated that most of the target compounds possessed in vitro antifungal activity against fluconazole-resistant Trichophyton rubrum and Cryptococcus neoformans. Several compounds (e.g., 40 and 4r) showed satisfactory activity, which makes them valuable for further research. Based on these results, preliminary SARs were summarized to serve as a foundation for the further investigation of antifungal drugs.

Acknowledgments: We greatly appreciate the funding support for this research provided by the National Natural Science Foundation of China (Grant No. 81573292).

Author Contributions: Zhen Liang designed and carried out the experiments and wrote the paper; Hang Xu, Ye Tian, Mengbi Guo assisted in experiments; Xin Su supervised and directed the biological assays; Chun Guo supervised the whole experiment and provided technical guidance. All authors have read and approved the final manuscript.

Conflicts of Interest: The authors declare no conflict of interest.

\section{References}

1. Enoch, D.A.; Ludlam, H.A.; Brown, N.M. Invasive fungal infections: A review of epidemiology and management options. J. Med. Microbiol. 2006, 55, 809-818. [CrossRef] [PubMed]

2. Kathiravan, M.K.; Salake, A.B.; Chothe, A.S.; Dudhe, P.B.; Watode, R.P.; Mukta, M.S.; Gadhwe, S. The biology and chemistry of antifungal agents: A review. Bioorg. Med. Chem. 2012, 20, 5678-5698. [CrossRef] [PubMed]

3. Groll, A.H.; Piscitelli, S.C.; Walsh, T.J. Clinical pharmacology of systemic antifungal agents: A comprehensive review of agents in clinical use, current investigational compounds, and putative targets for antifungal drug development. Adv. Pharmacol. 1998, 44, 343-500. [PubMed]

4. Kontoyiannis, D.P.; Lewis, R.E. Antifungal drug resistance of pathogenic fungi. Lancet 2002, 359, 1135-1144. [CrossRef]

5. Boutin, J.A. Myristoylation. Cell. Signal. 1997, 9, 15-35. [CrossRef]

6. Gordon, J.I.; Duronios, R.J.; Rudnicks, D.A.; Adamss, S.P.; Coke1, G.W. Protein N-myristoylation. J. Biol. Chem. 1991, 266, 8647-8650. [PubMed]

7. Weinberg, R.A.; Mcwherter, C.A.; Freeman, K.; Wood, D.C.; Gordon, J.I.; Lee, S.C. Genetic studies reveal that myristoylCoA: Protein N-myristoyltransferase is an essential enzyme in Candida albicans. Mol. Microbiol. 1995, 16, 241-250. [CrossRef] [PubMed]

8. Lodge, J.K.; Jackson-machelski, E.; Toffalettit, D.L.; Perfectt, J.R.; Gordon, J.I. Targeted gene replacement demonstrates that myristoylCoA: Protein $N$-myristoyltransferase is essential for viability of Cryptococcus neoformans. Proc. Natl. Acad. Sci. USA 1994, 91, 12008-12012. [CrossRef] [PubMed]

9. Sogabe, S.; Masubuchi, M.; Sakata, K.; Fukami, T.A.; Morikami, K.; Shiratori, Y.; Ebiike, H.; Kawasaki, K.; Aoki, Y.; Shimma, N.; et al. Crystal structures of Candida albicans $N$-myristoyltransferase with two distinct inhibitors. Chem. Biol. 2002, 9, 1119-1128. [CrossRef]

10. Devadas, B.; Freeman, S.K.; Zupec, M.E.; Lu, H.F.; Nagarajan, S.R.; Kishore, N.S.; Lodge, J.K.; Kuneman, D.W.; McWherter, C.A.; Vinjamoori, D.V.; et al. Design and synthesis of novel imidazole-substituted dipeptide amides as potent and selective inhibitors of Candida albicans myristoylCoA: Protein N-myristoyltransferase and identification of related tripeptide inhibitors with mechanism based antifungal act. J. Med. Chem. 1997, 40, 2609-2625. [CrossRef] [PubMed]

11. Nagarajan, S.R.; Devadas, B.; Zupec, M.E.; Freeman, S.K.; Brown, D.L.; Lu, H.; Mehta, P.P.; Kishore, N.S.; McWherter, C.A.; Getman, D.P.; et al. A Conformationally constrained ( $p$-( $\omega$-aminoalkyl)phenacetyl)L-seryl-L -lysyl dipeptide amides as potent peptidomimetic inhibitors of Candida albicans and human myristoylCoA: Protein N-myristoyl transferase. J. Med. Chem. 1997, 40, 1422-1438. [CrossRef] [PubMed] 
12. McWherter, C.A.; Rocque, W.J.; Zupec, M.E.; Freeman, S.K.; Brown, D.L.; Devadas, B.; Getman, D.P.; Sikorski, J.A.; Gordon, J.I. Scanning alanine mutagenesis and de-peptidization of a Candida albicans myristoylCoA: Protein $N$-myristoyltransferase octapeptide substrate reveals three elements critical for molecular recognition. J. Biol. Chem. 1997, 272, 11874-11880. [CrossRef] [PubMed]

13. Parang, K.; Knaus, E.E.; Wiebe, L.I.; Sardari, S.; Daneshtalab, M.; Csizmadia, F. Synthesis and antifungal activities of myristic acid analogs. Arch. Pharm. 1996, 329, 475-482. [CrossRef]

14. Sheng, C.; Xu, H.; Wang, W.; Cao, Y.; Dong, G.; Wang, S.; Che, X.; Ji, H.; Miao, Z.; Yao, J. Design, synthesis and antifungal activity of isosteric analogues of benzoheterocyclic $N$-myristoyltransferase inhibitors. Eur. J. Med. Chem. 2010, 45, 3531-3540. [CrossRef] [PubMed]

15. Ebara, S.; Naito, H.; Nakazawa, K.; Ishii, F.; Nakamura, M. FTR1335 is a novel synthetic inhibitor of Candida albicans N-myristoyltransferase with fungicidal activity. Biol. Pharm. Bull. 2005, 28, 591-595. [CrossRef] [PubMed]

16. Masubuchi, M.; Ebiike, H.; Kawasaki, K.; Sogabe, S.; Morikami, K.; Shiratori, Y.; Tsujii, S.; Fujii, T.; Sakata, K.; Hayase, M.; et al. Synthesis and biological activities of benzofuran antifungal agents targeting fungal N-myristoyltransferase. Bioorg. Med. Chem. 2003, 11, 4463-4478. [CrossRef]

17. Ebiike, H.; Masubuchi, M.; Liu, P.; Kawasaki, K.; Morikami, K.; Sogabe, S.; Hayase, M.; Fujii, T.; Sakata, K.; Shindoh, H.; et al. Design and synthesis of novel benzofurans as a new class of antifungal agents targeting fungal N-myristoyltransferase. Part 2. Bioorg. Med. Chem. Lett. 2002, 12, 607-610. [CrossRef]

18. Kawasaki, K.I.; Masubuchi, M.; Morikami, K.; Sogabe, S.; Aoyama, T.; Ebiike, H.; Niizuma, S.; Hayase, M.; Fujii, T.; Sakata, K.; et al. Design and synthesis of novel benzofurans as a new class of antifungal agents targeting fungal N-myristoyltransferase. Part 3. Bioorg. Med. Chem. Lett. 2003, 13, 87-91. [CrossRef]

19. Masubuchi, M.; Kawasaki, K.; Ebiike, H.; Ikeda, Y.; Tsujii, S.; Sogabe, S.; Fujii, T.; Sakata, K.; Shiratori, Y.; Aoki, Y.; et al. Design and synthesis of novel benzofurans as a new class of antifungal agents targeting fungal N-myristoyltransferase. Part 1. Bioorg. Med. Chem. Lett. 2001, 11, 1833-1837. [CrossRef]

20. Hejchman, E.; Ostrowska, K.; Maciejewska, D.; Kossakowski, J.; Courchesne, W.E. Synthesis and antifungal activity of derivatives of 2- and 3-benzofurancarboxylic acids. J. Pharmacol. Exp. Ther. 2012, 343, 380-388. [CrossRef] [PubMed]

21. Ryu, C.K.; Kim, Y.H.; Nho, J.H.; Hong, J.A.; Yoon, J.H.; Kim, A. Synthesis and antifungal activity of furo(2,3-f)quinolin-5-ols. Bioorg. Med. Chem. Lett. 2011, 21, 952-955. [CrossRef] [PubMed]

22. Gündoğdu-Karaburun, N.; Benkli, K.; Tunali, Y.; Uçucu, Ü.; Demirayak, Ş. Synthesis and antifungal activities of some aryl (3-(imidazol-1-yl/triazol-1-ylmethyl) benzofuran-2-yl) ketoximes. Eur. J. Med. Chem. 2006, 41, 651-656. [CrossRef] [PubMed]

23. Benkli, K.; Gündoĝdu-Karaburun, N.; Karaburun, A.C.; Uçucu, Ü.; Demirayak, S.; Kiraz, N. Synthesis and antifungal activities of some aryl (3-methyl-benzofuran-2-yl) ketoximes. Arch. Pharm. Res. 2003, 26, 202-206. [CrossRef] [PubMed]

24. Mohammadi-Khanaposhtani, M.; Saeedi, M.; Zafarghandi, N.S.; Mahdavi, M.; Sabourian, R.; Razkenari, E.K.; Alinezhad, H.; Khanavi, M.; Foroumadi, A.; Shafiee, A.; et al. Potent acetylcholinesterase inhibitors: Design, synthesis, biological evaluation, and docking study of acridone linked to 1,2,3-triazole derivatives. Eur. J. Med. Chem. 2015, 92, 799-806. [CrossRef] [PubMed]

25. Weide, T.; Saldanha, S.A.; Minond, D.; Spicer, T.P.; Fotsing, J.R.; Spaargaren, M.; Frère, J.-M.; Bebrone, C.; Sharpless, K.B.; Hodder, P.S.; et al. NH-1,2,3-triazole inhibitors of the VIM-2 metallo- $\beta$-lactamase. Med. Chem. Lett. 2010, 1, 150-154. [CrossRef] [PubMed]

26. Giffin, M.J.; Heaslet, H.; Brik, A.; Lin, Y.-C.; Cauvi, G.; Wong, C.-H.; McRee, D.E.; Elder, J.H.; Stout, C.D.; Torbett, B.E. A copper(I)-catalyzed 1,2,3-triazole azide-alkyne click compound is a potent inhibitor of a multidrug-resistant HIV-1 protease variant. J. Med. Chem. 2008, 51, 6263-6270. [CrossRef] [PubMed]

27. Xu, S.; Zhuang, X.; Pan, X.; Zhang, Z.; Duan, L.; Liu, Y.; Zhang, L.; Ren, X.; Ding, K. 1-Phenyl-4-benzoyl$1 H$-1,2,3-triazoles as orally bioavailable transcriptional function suppressors of estrogen-related receptor $\alpha$. J. Med. Chem. 2013, 56, 4631-4640. [CrossRef] [PubMed]

28. Kumar, D.; Beena; Khare, G.; Kidwai, S.; Tyagi, A.K.; Singh, R.; Rawat, D.S. Synthesis of novel 1,2,3-triazole derivatives of isoniazid and their in vitro and in vivo antimycobacterial activity evaluation. Eur. J. Med. Chem. 2014, 81, 301-313. [CrossRef] [PubMed] 
29. Kamal, A.; Hussaini, S.M.A.; Sucharitha, M.L.; Poornachandra, Y.; Sultana, F.; Ganesh Kumar, C. Synthesis and antimicrobial potential of nitrofuran-triazole congeners. Org. Biomol. Chem. 2015, 13, 9388-9397. [CrossRef] [PubMed]

30. Dai, Z.-C.; Chen, Y.-F.; Zhang, M.; Li, S.-K.; Yang, T.-T.; Shen, L.; Wang, J.-X.; Qian, S.-S.; Zhu, H.-L.; Ye, Y.-H. Synthesis and antifungal activity of 1,2,3-triazole phenylhydrazone derivatives. Org. Biomol. Chem. 2015, 13, 477-486. [CrossRef] [PubMed]

31. Lima-Neto, R.G.; Cavalcante, N.N.M.; Srivastava, R.M.; Mendonça, F.J.B.; Wanderley, A.G.; Neves, R.P.; dos Anjos, J.V. Synthesis of 1,2,3-triazole derivatives and in vitro antifungal evaluation on Candida strains. Molecules 2012, 17, 5882-5892. [CrossRef] [PubMed]

32. Shaikh, M.H.; Subhedar, D.D.; Khan, F.A.K.; Sangshetti, J.N.; Shingate, B.B. 1,2,3-Triazole incorporated coumarin derivatives as a potential antifungal and antioxidant agents. Chin. Chem. Lett. 2015, 27, 295-301. [CrossRef]

33. Wang, Y.; Xu, K.; Bai, G.; Huang, L.; Wu, Q.; Pan, W.; Yu, S. Synthesis and antifungal activity of novel triazole compounds containing piperazine moiety. Molecules 2014, 19, 11333-11340. [CrossRef] [PubMed]

34. Zhu, J.; Sheng, C.-Q.; Zhang, W.-N. N-Myristoyltransferase: A novel antifungal target. Acta Pharm. Sin. 2005, 40, 775-781.

35. Clinical Laboratory Standards Institute (CLSI). Reference Method for Broth Dilution Testing of Yeasts, 3rd ed.; CLSI: Wayne, PA, USA, 2008.

Sample Availability: Samples of the compounds $\mathbf{1 a}, \mathbf{b}, \mathbf{2} \mathbf{a}, \mathbf{b}$ and $\mathbf{4 a - r}$ are available from the authors.

(C) 2016 by the authors; licensee MDPI, Basel, Switzerland. This article is an open access article distributed under the terms and conditions of the Creative Commons Attribution (CC-BY) license (http://creativecommons.org/licenses/by/4.0/). 